I work because I very much like to be here. (Julia, age 17)

I like to be with the children, um, play with them, um, talk to them so they are happy that, that I am working with them ... I work because I like to, I like this type of work, working with special children. (Amelia, age 29)

I like to be close to the children. Also, um, what I like the most is to help the children do well. To be useful and to click with them, so I can say, 'I did it'. (Javier, age 41)

In Mexico, both public and private vocational training programmes exist for people with intellectual disabilities, providing skills and sometimes work placements. Vocational training and experience acquired from public services in Mexico were described as follows by interviewees who had used them:

I come from the National Family Development [public] system. They put me in the company ... they teach you the basics first, the basics but they teach you, they practise some things with you. Then later they place you in a company or a place. But I also took courses in carpentry, upholstery, wood carving, leather embossing ... I got into the public system and worked in industry. (Alejandro, age 34).

I was in a school ... there were a lot [of things] to study, whatever you wanted. There was cooking, carpentry and bakery. I chose bakery and I graduated. (Andrea, age 41)

At the public home, well, that is, there when you went to school, you learned, and like they taught me carpentry and that, and also they taught us to take care of the little ones. So I was catching on to what they told us. What I do here at the clinic [special education centre] and everything. (Ana, age 19)

\section{Conclusions}

This study supports the idea that it is important to combine training in basic, practical skills for independent living with services to support social inclusion as well as vocational training and job placement services for people with intellectual disability. Our findings also suggest the need for public policy to support community and employment inclusion and the importance of public campaigns to facilitate it.

\title{
Psychiatry in the UK: an overview
}

\section{Vicky Banks ${ }^{1}$ MB BS MRCGP FRCPsych, Geoff Searle ${ }^{2}$ MB BS BSc FRCPsych and Rachel Jenkins ${ }^{3}$ MB BChir MD(Cantab) FRCPsych FFOHM FRSPH}

\begin{abstract}
${ }^{1}$ Consultant in Older Persons' Mental Health and Deputy Medical Director, Hampshire Partnership Foundation Trust, and Associate Dean, Royal College of Psychiatrists, email Vicky.Banks@hantspt-sw.nhs.uk; ${ }^{2}$ Crisis Team Consultant, Dorset Healthcare Foundation Trust, Core and Quality Training Programme Director, Wessex Deanery; ${ }^{3}$ Director and Professor of Psychiatry, WHO Collaborating Center and Section for Mental Health Policy, Institute of Psychiatry, London, UK
\end{abstract}

$T^{\text {his }}$ he National Health Service (NHS) serves the UK through four devolved organisations for England, Scotland, Wales and Northern Ireland. It is one of the largest public healthcare systems in the world, universal and free at the point of delivery. Its key challenge is to maintain this approach within tight financial constraints, while embracing new technologies, treatments and styles of service delivery, as well as meeting the health needs of an ageing population.

The population of the UK was 61792000 in mid-2009. Children aged under 16 represented approximately one in five of the total population, around the same proportion as those of retirement age (over 65). In mid-2009 the average age of the population was 39.5 years, up from 37.3 in 1999. Population growth is greatest in the over-85s, who currently number around 1.4 million, a figure which is estimated to reach 3.5 million by 2034 , which will represent $5 \%$ of the population.

\section{Mental health in the UK}

Mental illness contributes $22.8 \%$ of the total burden of disability-adjusted life years (DALYS) in the UK (World Health
Organization, 2008). One in six adults has a mental health problem at any one time (World Health Organization, 2004).

Half of those with a long-term mental illness have it by the age of 14 (Kim-Cohen et al, 2003) and three-quarters by their mid-20s (Kessler \& Wang, 2007). The most deprived communities in the UK have the poorest mental health and physical health (McManus et al, 2009). People with severe mental illness die on average 20 years earlier than the general population. Mental health problems cost England approximately $\mathrm{f105}$ billion each year, including costs of lost productivity and the wider impacts on well-being (Centre for Mental Health, 2010), and represent the largest single cost to the NHS, accounting for $11 \%$ of the secondary care budget (Department of Health, 2009).

Further key statistics are presented in Box 1.

\section{Mental health service policy development and delivery}

When it was created in 1948, the NHS took over a large number of old mental asylums. The movement towards 
Box 1 Mental illness in England: some illustrative figures

- $10 \%$ of children and young people have a mental disorder. Of 5- to 16-year-olds, $6 \%$ have conduct disorder (Green et al, 2005), 4\% an emotional disorder (Green et al, 2005) and $18 \%$ subthreshold conduct disorder (Colman et al, 2009)

- $17.6 \%$ of adults in England have at least one common mental disorder and a similar proportion have symptoms which do not fulfil full diagnostic criteria for common mental disorder (McManus et al, 2009)

- Postnatal depression affects $13 \%$ of women following childbirth (O'Hara \& Swain, 1996)

- In any one year, $0.4 \%$ of the population suffer from a psychosis (McManus et al, 2009) and a further $5 \%$ from subthreshold psychosis (Van Os et al, 2009)

- $5.4 \%$ of men and $3.4 \%$ of women have a personality disorder (Singleton et al, 2001); $0.3 \%$ of adults have antisocial personality disorder (McManus et al, 2009)

- $24 \%$ of adults have hazardous patterns of drinking, $6 \%$ have alcohol dependence (Singleton et al, 2001), 21\% tobacco dependence (McManus et al, 2009) and 3\% dependence on illegal drugs (Singleton et al, 2001)

- $25 \%$ of older people have depressive symptoms which require intervention: $11 \%$ have mild depression and $2 \%$ severe depression (Godfrey et al, 2005); the risk increases with age $-40 \%$ of over- 85 s are affected

- $20-25 \%$ of people with dementia have major depression, whereas $20-30 \%$ have minor or subthreshold depression (Amore et al, 2007)

- Dementia affects $5 \%$ of people aged over 65 and $20 \%$ of those aged over 80 (Knapp \& Prince, 2007)

- In care homes, $40 \%$ of residents have depression, $50-80 \%$ dementia and $30 \%$ anxiety (Godfrey et al, 2005)

- A third of people who care for an older person with dementia have depression (Milne et al, 2001).

community care for people with severe mental illness started in the 1950s with the advent of phenothiazines and the exploration of rehabilitation methods in community settings. The movement received government policy endorsement in the 1970s. Research from the 1960s through to the 1980s demonstrated the damaging effects of institutionalisation and the improved health and social outcomes which accompanied deinstitutionalisation. A major Department of Health drive to close the large asylums started in the 1980s, accompanied by expansion of district community teams and the development of comprehensive local care systems. The Care Programme Approach (CPA) was introduced in 1990 to ensure systematic assessment of needs, individual tailored care plans, regular review and assignment of a key worker. Mental health was prioritised in the 1992 white paper The Health of the Nation, which set outcome targets to reduce morbidity from mental illness and suicide. This was followed by frameworks for intersectoral working (Building Bridges, 1995) and for local comprehensive care (The Spectrum of Care, 1996). A national psychiatric morbidity survey programme was started in 1993 (see http://www. mentalhealthsurveys.co.uk).

The Mental Health National Service Framework (NSF) was established in 1999; it sets standards of care for suicide prevention, access to services, mental health promotion, and carer support and involvement, with prescribed models of service delivery in both primary and secondary care. In 2000, the NHS Plan aimed to strengthen community care and reduce the use of acute in-patient beds; this was followed by major investment, which led to an additional 700 mental health teams, 1300 consultant psychiatrists, 2700 clinical psychologists and 10000 mental health nurses, who were deployed in highly specialised teams (community mental health teams, crisis resolution and home treatment teams, assertive outreach teams and early intervention teams); these were able to reduce admissions, but their operation was often rather fragmented.

The past few years have seen more highly structured care delivery, using care pathways. Consultant psychiatrists use their expertise at the beginning of the care pathways, assess complex cases, review those in crisis and advise team members and primary care staff (Royal College of Psychiatrists, 2010a). Psychological treatments have been expanded with a tiered programme of brief psychotherapeutic interventions (particularly cognitive-behavioural therapy) provided by the Improving Access to Psychological Therapies (IAPT) programme (Department of Health, 2008).

Service users and their carers have been increasingly involved in service development, supported by a number of voluntary organisations. An important focus has been the 'personalisation' of care, which has been led by a new national body, Health Watch, which has pilot projects already established in a number of services.

Both public and private mental health services are regularly inspected, most recently by the Care Quality Commission (CQC) (see http://www.cqc.org.uk), which also monitors the use of the Mental Health Act, and protects the rights and interests of detained patients.

A recent national patient satisfaction survey showed that $77 \%$ of community patients rate their care as good, very good or excellent. The suicide rate in England has fallen steadily since 1990, alongside implementation of a national suicide prevention strategy (National Mental Health Development Unit, 2009) and the World Health Organization has declared that England has the best services in Europe (see Appleby, 2007).

The past few decades have seen continuous organisational change in the NHS, ranging from the separation of the purchase and provision of services in the late 1980s to several moves to achieve greater autonomy for local health providers. The 2010 white paper Equity and Excellence: Liberating the NHS sets out plans to form new purchasing organisations run by family physicians ('GP consortia'), while the new mental health strategy, 'No Health Without Mental Health' (with a supporting paper, Delivering Better Mental Health Outcomes; HM Government, 2011a,b), adopts a life course approach, as advocated by the 'Foresight' report on mental capital and well-being (Cooper et al, 2008), and aims to create parity of esteem between physical and mental health. These have been followed by a statement on public mental health from the Royal College of Psychiatrists (2010b).

Many of the developments described above relate to England but similar challenges face the devolved administrations in the other countries of the UK, which are evolving their own tailored responses. 


\section{Mental health legislation}

There have been a number of recent changes in mental health legislation. The essential principles of the Mental Health Act 1983 remain unchanged, but the Mental Health Act 2007 (England and Wales) introduced community treatment orders (CTOs), changes in professional roles and additional safeguards for patients receiving electroconvulsive therapy.

The Mental Capacity Act 2005, followed by Deprivation of Liberty Safeguards 2007 (DoLS), provides a legal framework for those who lack capacity, with key principles, procedures and safeguards in line with human rights legislation.

There is a similar Mental Health (Care and Treatment) (Scotland) Act 2003 and new legislation for Northern Ireland covering capacity and mental health is due in 2011.

\section{Undergraduate training}

In the UK there are 31 undergraduate medical schools which train doctors on behalf of the NHS $50 \%$ of these undergraduates will go on to become family physicians). Medicine is usually a first degree course, that is, entered directly from school, although some medical schools offer graduate entry and some offer an intercalated second degree. Training is guided by the UK General Medical Council (GMC) (see GMC, 2003). Learning has become both more learner led and more research based (including problem-based learning), with clinical experience earlier in training.

Psychiatry undergraduate training lasts 6-12 weeks but, in order to achieve parity with physical health, this should be increased to reflect the prevalence of mental health problems in the community.

\section{Postgraduate training in psychiatry}

Training in psychiatry follows a 6-year programme: 3 years in core training; then, after passing their professional examinations, trainees re-apply for higher training and a further 3 years as a (sub)specialty trainee. Successful completion leads to the Certificate of Completion of Training (CCT) in psychiatry. Recruitment into psychiatry is at a low level, with many unfilled posts in core training across the UK.

The education of the trainee is actively managed within a structured framework of competencies, which are continuously assessed through workplace-based assessments (WPBAs) - which are now web based. Progress through training is managed by an annual review of competency progression (ARCP), which is informed by an electronic portfolio of experience, hosted by the Royal College of Psychiatrists. Core trainees must pass the MRCPsych examination (which comprises three written papers and a clinical examination) to progress to advanced training. The curricula for the new training programmes are approved and quality assured by the GMC, which recently took over responsibility for postgraduate education.

There are 21 deaneries responsible for the delivery of postgraduate medical education in England, Scotland, Northern Ireland and Wales. In 2006-07, deaneries introduced 'specialty schools', which, together with the Royal College of Psychiatrists, lead national recruitment and training, maintain standards and support innovation and diversity in psychiatry education, and work closely with the College's Psychiatric Trainees' Committee.

\section{Research and academic psychiatry}

Research in mental health is undertaken by universities, NHS trusts and charities. There has been a growing trend to involve users and carers in research design and conduct, and all research with human participants has to receive prior ethical approval. There are a variety of UK funding sources, including the Department of Health, the Medical Research Council, the Economic and Social Research Council, the Wellcome Trust, and smaller foundations, as well as international sources such as the European Union. Many UK researchers have strong links to researchers in other countries, and participate in international studies. Universities run master's degree courses and $\mathrm{PhD}$ training programmes, and some funders offer PhD scholarships. A number of highimpact mental health research journals are based in the UK. The UK Department of Health also funds the regular production of 'good practice' guidelines by the National Institute for Health and Clinical Excellence, based on systematic reviews of the research evidence.

\section{Conclusions}

In the UK the delivery of mental healthcare is under constant change, against a backdrop of regular reform of the NHS. Recent changes in legislation and organisation offer opportunities to improve the mental health of the UK. To deliver these changes strong consultant leadership, increased recruitment to psychiatry, and a drive for equity for physical and mental healthcare in the UK are needed.

\section{References}

Amore, M., Taqariello, P., Laterza, C., et al (2007) Subtypes of depression in dementia. Archives of Gerontology and Geriatrics, 44, 23-33.

Appleby, L. (2007) Mental Health Ten Years On: Progress on Mental Health Care Reform. Department of Health.

Centre for Mental Health (2010) The Economic and Social Costs of Mental Health Problems in 2009/10. Centre for Mental Health. Available at http://www.centreformentalhealth.org.uk/pdfs/Economic and_social_costs_2010.pdf (last accessed March 2011).

Colmañ, I., Murray, J., Abbott, R. A., et al (2009) Outcomes of conduct problems in adolescence: 40 year follow-up of a national cohort. BMJ, 338, a2981.

Cooper, C., Field, J., Goswami, U., et al (2008) Mental Capital and WellBeing Final Project Report. Government Office for Science.

Department of Health (2008) Improving Access to Psychological Therapies Implementation Plan: National Guidelines for Regional Delivery. DH.

Department of Health (2009) Departmental Report 2009: The Health and Personal Social Services Programmes. DH. Available at http:// www.official-documents.gov.uk/document/cm75/7593/7593.pdf (last accessed March 2011).

GMC (2003) Tomorrow's Doctors. General Medical Council.

Godfrey, M., Townsend, J., Surr, C., et al (2005) Prevention and Service Provision: Mental Health Problems in Later Life. Institute of Health 
Sciences and Public Health Research, Leeds University, and Division of Dementia Studies, Bradford University.

Green, H., McGinnity, A., Meltzer, H., et al (2005) Mental Health of Children and Young People in Great Britain, 2004. Office for National Statistics.

HM Government (2011a) No Health Without Mental Health: A Cross Government Mental Health Outcomes Strategy for People of All Ages. Department of Health.

HM Government (2011b) No Health Without Mental Health: Delivering Better Mental Health Outcomes for People of All Ages. Department of Health.

Kessler, R. \& Wang, P. (2007) The descriptive epidemiology of commonly occurring mental disorders in the United States. Annual Review of Public Health, 29, 115-129.

Kim-Cohen, J., Caspi, A., Moffitt, T., et al (2003) Prior juvenile diagnoses in adults with mental disorder. Archives of General Psychiatry, 60, 709-717.

Knapp, M. \& Prince, M. (2007) Dementia UK: A Report into the Prevalence and Cost of Dementia. Alzheimer's Society.

McManus, S., Meltzer, H., Brugha, T., et al (2009) Adult Psychiatric Morbidity in England, 2007: Results of a Household Survey. NHS Information Centre for Health and Social Care.

Milne, A., Hatzidimitriadou, E., Chryssatholoplou, C., et al (2001) Caring in Later Life: Reviewing the Role of Older Carers. Help the Aged.
National Mental Health Development Unit (2009) National Suicide Prevention Strategy for England: Annual Report on Progress 2008. NMHDU.

O'Hara, M. W. \& Swain, A. M. (1996) Rates and risk of postpartum depression - a meta analysis. International Review of Psychiatry, 8, 37-54

Royal College of Psychiatrists (2010a) Looking Ahead: Future Development of UK Mental Health Services: Recommendations from a Royal College of Psychiatrists' Enquiry. Occasional Paper OP75. Royal College of Psychiatrists.

Royal College of Psychiatrists (2010b) No Health Without Public Mental Health: The Case for Action. Position Statement PS4. Royal College of Psychiatrists.

Singleton, N., Bumpstead, R., O'Brien, M., et al (2001) Psychiatric Morbidity Among Adults Living in Private Households, 2000. TSO.

Van Os, J., Linscott, R. J., Myin-Germeys, P., et al (2009) A systematic review and meta analysis of the psychosis continuum: evidence for a psychosis-proneness-persistence impairment model of psychotic disorder. Psychological Medicine, 39, 179-195.

World Health Organization (2004) Projections of Mortality and Global Burden of Disease 2004-2030. WHO.

World Health Organization (2008) Global Burden of Disease Report. WHO. Available at http://www.who.int/healthinfo/global burden disease/estimates_country/en/index.html (last accessed March 2011).

\section{Psychiatry in paradise - the Solomon Islands}

\section{Ashok N. Singh ${ }^{1}$ MD and Paul Orotaloa ${ }^{2}$ MD}

${ }^{1}$ Consultant Psychiatrist, Department of Psychiatry, Pilgrim Hospital, Boston, Linconshire, UK, email Ashok.Singh@LPFT.nhs.uk; ${ }^{2}$ Consultant Psychiatrist, Mental Health Unit, National Referral Hospital, Honiara, Solomon Islands

\begin{abstract}
- he Solomon Islands is situated in the South Pacific Ocean and is a low-income country. It comprises nearly 1000 islands with a total land area of $304000 \mathrm{~km}^{2}$ spread over a sea area of about $1500000 \mathrm{~km}^{2}$, making communications, travel and service delivery difficult and creating inequities in access. The population of the Solomon Islands was estimated to be just over 580000 in 2008, and is young, with $42 \%$ aged under 15 years (Solomon Islands Ministry of Health, 2006). The majority of the people are Melanesian (93\%) and $98 \%$ of the population belong to a Christian church. The population is, though, extremely diverse, with 91 indigenous languages and dialects being spoken, in addition to the Solomon Islands pijin (the most common language) and English (the official national language). Over $83 \%$ of the population live in rural areas, where subsistence agriculture, fishing and food gathering are the main sources of income. There is no substantial tourist industry. The gross domestic product (GDP) is US $\$ 1.5$ billion and annual per capita income is approximately US\$2800 (International Monetary Fund, 2009). Total expenditure on health represented $5.6 \%$ of GDP but only $1 \%$ of the total health budget is allocated to mental health (World Health Organization, 2005).
\end{abstract}

\section{Mental health policy and legislation}

Mental health has been attracting increasing attention in the Solomon Islands, with growing support for the adoption of a broad national mental health policy. Following agreement between the Ministry of Health and medical services, and the World Health Organization, a short-term consultant was mobilised from October 2008 to January 2009 to assist with the development of this policy. As part of the intensive consultation process, over 120 individuals were interviewed, including senior national and provincial staff of the Ministry of Health, non-governmental organisations, church leaders and relatives and carers for people with mental disorders. The feedback from a workshop and the consultation process was then incorporated into the national mental health policy.

\section{Mental health legislation}

The Mental Treatment Act 1970 consolidated the law relating to people of unsound mind and makes better provision for the care of persons suffering from mental disorders 